\title{
Shaping Complex Identities. Managing Dynamic Brands for Educational Institutions
}

\author{
Veronica Dal Buono \\ University of Ferrara, Department of Architecture, \\ Ferrara, Italy \\ \{veronica.dalbuono\}@unife.it
}

\begin{abstract}
The essay focuses on a set of case studies of educational institutes that recently turned their traditional visual identity into "dynamic". "Dynamic identities" - as defined by literature - can be considered the most innovative outcomes in branding, heavily contaminated by digital tools and strategies, including visual expressions that are variable (differing in space and time), generative (processes connecting to parametric methodologies) and even relational (emphasizing the open and participative approach with users). Design concepts as the one quoted, have reached an application and diffusion phase that warrants recognition of the results in order to transfer the knowledge to the discipline of visual communication so as to be applied in the reality of branding processes for educational institutions.
\end{abstract}

Keywords: dynamic identities / visual identity / institutional communication.

\section{To communicate educational institutions as complex organism}

The realm of cultural and educational institutions, completely incorporated into a globalized society, has clearly assimilated the principles of branding, using communication and visual design tools effectively as the world of corporations has [1].

Moving in a highly competitive environment to achieve results in terms of reputation and number of enrolled students, these organizations implement their differentiation by adopting elements of visual communication in innovative terms.

In this context, visual identity has to answer to multiple levels of purposes: it must reflect the key values which define the group, echo the core mission of the institution (knowledge exchange, talent development, public engagement), represent the complex structure of the organization and, most importantly, its community. 


\section{The shift from static to dynamic identities}

Observing the communication process, while the components of the community, both internal and external, are sending out (visual) messages, official or not official, they generate a collective opinion - an "image" - regarding the institution. This "image" is the core of the corporate identity and needs to be addressed and designed. With the rise of digital and social media, in which sender and recipient use not a one-way media (as the traditional channels) but a relational one (everyone can respond and others can see the response), even the institutional communication has become more complex and demands appropriate tools, involving the visual identity process.

It's possible to say that the level of complexity has exceeded the capability of the traditional identity, based and founded on one single trademark (logo or seal) in which the symbol communicates the same message repeatedly, never changing according to time and context [2].

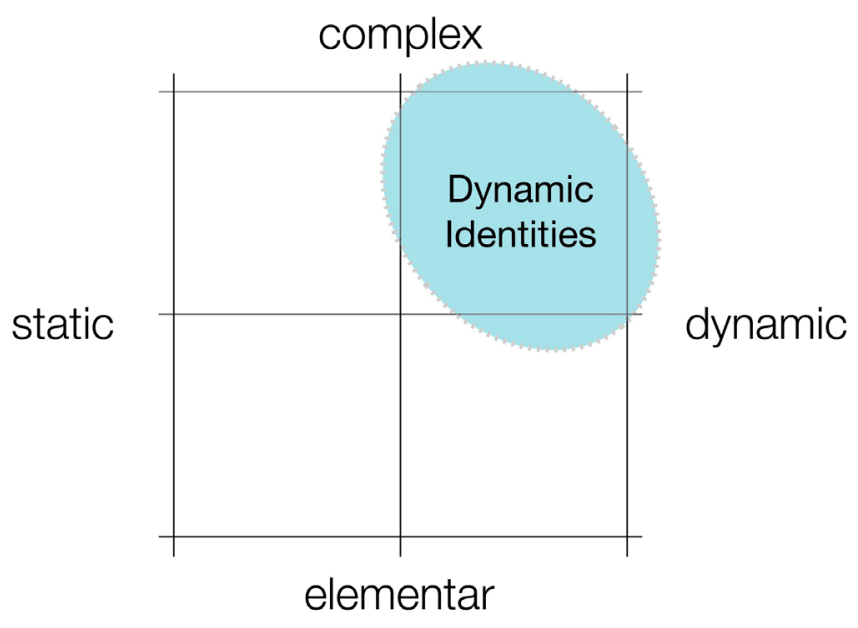

Fig. 1. The position of dynamic identities in the matrix of visual systems.

The aim of this essay is to outline a new approach occurred in shaping institutional identities, observing that in recent years there has been a considerable growing interest in re-branding institutions using dynamic visual identities.

We argue that this evolution is something more than a trend but a relevant shift of method in how educational organizations communicate themselves [3].

Dynamic brands, rather than the ultimate, pre-formulated visual message expressed by a logo, design visual languages. As a matter of fact, while a logo-based identity is the representation of a single idea, a "dynamic identity" (or "flexible" or "post-logo") [4] [5] is a system of elements that can be used by an organization as tools to formulate a multitude of different messages, adapting to varying formats, sizes and contexts. 
This could be considered as the contemporary response to the increased complexity in communication of multiple organizations.

\subsection{Highlighting significant examples}

The following case studies reveal how a systemic approach ensures the recognisability of the institution, through an overall design of multiple and flexible elements.

Let's take the Ringling College as our first example, known to be the first institution to apply an "open" and "co-designed" identity. It transpired in 2008 and has set an example for other designs [6].

The metaphor used is a window that meets a background based on the same proportions (the golden section). The background is a varying patchwork of colours and images. The innovation was that these images could be chosen by an online mechanism, by each member of the college, as a visual voice of the whole community. With this new approach the main logo becomes "relational" and each member of the community is supposed to have his own identity. The variations of contents ensure flexibility while the static frame, as the main element, confirms the recognisability. Through variations the institution can modulate its tone of voice and can shift from a single, monotonous to a multidimensional (Fig. 2).
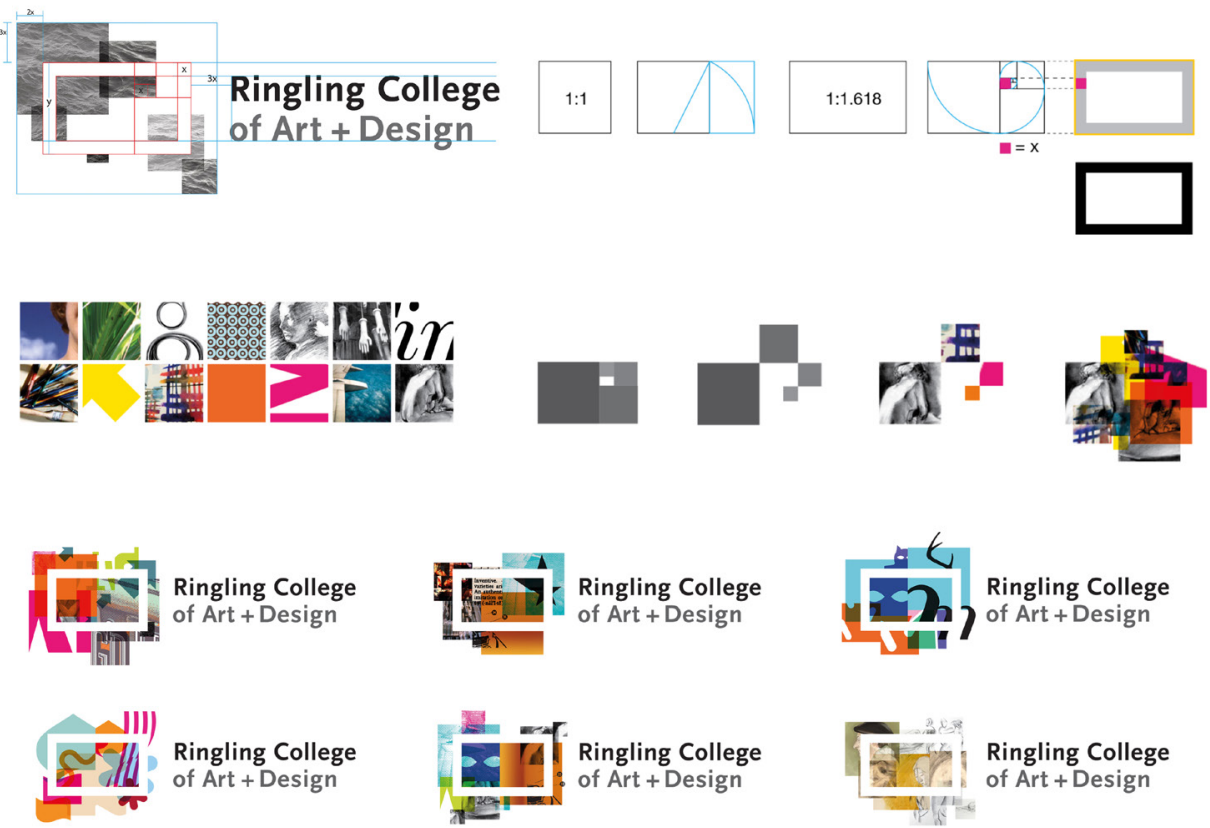

Ringling College of Art + Design

Fig. 2. Ringling College Identity by SamataMason / Collective / Multiple, 2007. 
Next example is the EAD Eindhoven Academy of Design, best known for its engagement with the student body and academic staff. As in the previous example, the metaphor is a frame and the customization is achieved through a written sign inside by each member of the Academy. (Fig. 3)

Thirdly, the OCAD Academy, in Canada, and its results of a workshop experienced by Bruce Mau with the inner students. The idea is more advanced than the previous ones. Customization is attained through drawings realized by highly qualified grad students. The coordinated image is supposed to be managed centrally by the institution (Fig. 4).

Moreover, in that same year, 2011, is the work by The Green Eyl for the Mit Media Lab. This project, so well documented in print and online resources, is no longer applied. It was one of the first projects in which Processing, the generative programme, was used to create 40,000 variations of the logo, one for each member of the Lab (Fig. 5).

Considered as a "celebration logo" of the 25th anniversary of the Lab, five years later Pentagram was asked to design a new permanent visual identity that now is applied. The difference from the previous design consists in the variations of the main logo, limited to the only 25 research centres that form the Lab (Fig. 5).
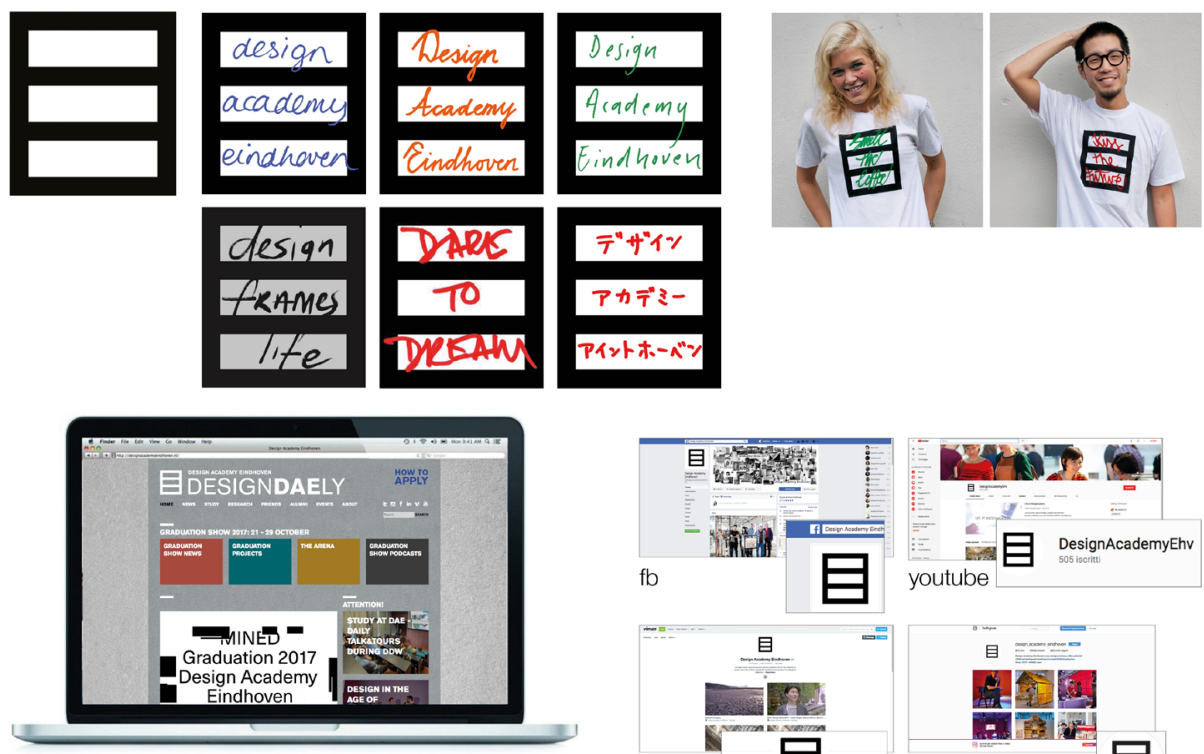

DAE website
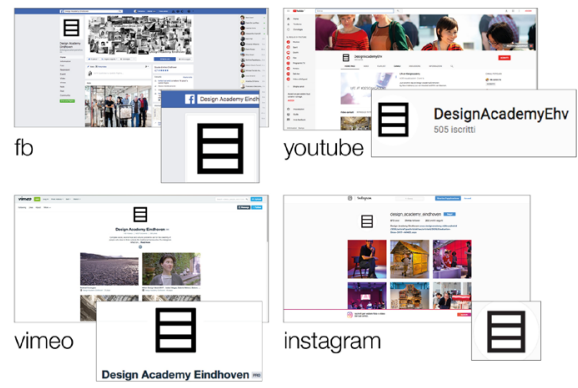

Fig. 3. Design Academy Eindhoven Identity by The Stone Twins, 2009. 

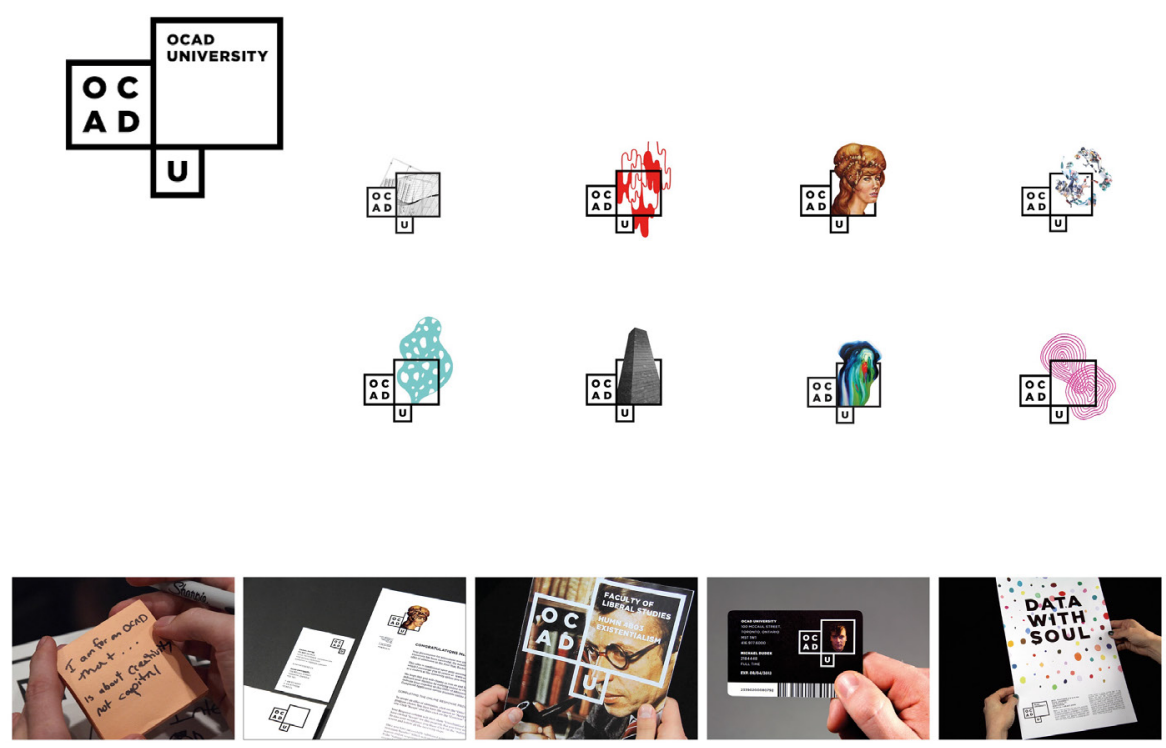

Fig. 4. OCAD University Identity by Bruce Mau with the students, 2011.
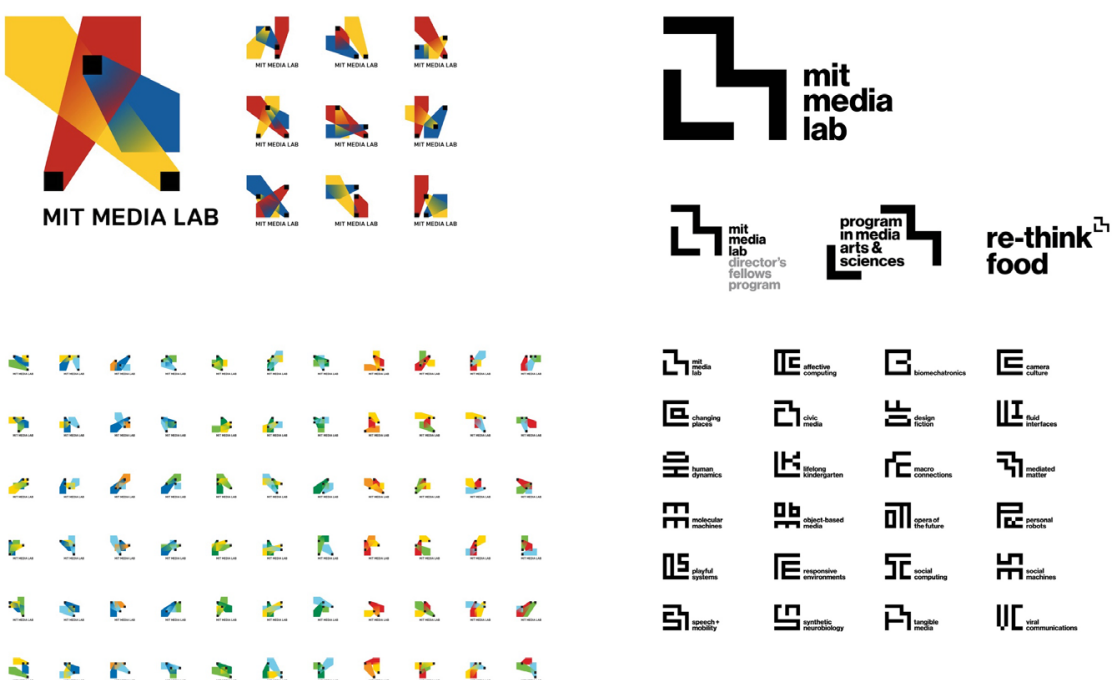

\begin{tabular}{|c|c|c|c|}
\hline 乙䒺 & $\mathbb{\square}$ & 巨。 & 드 \\
\hline 區 & 已凪 & 㟔 & 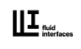 \\
\hline 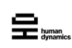 & 는 & 后 & औ= \\
\hline 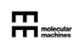 & 맴=ㄴ & 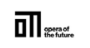 & 屈= \\
\hline ח & 压 & $\bar{J}=$ & 耑= \\
\hline & 乌 & 乃 & $\mathbb{U}[$ \\
\hline
\end{tabular}

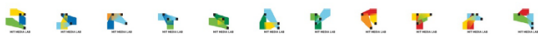

Fig. 5. Left: MIT Media Lab's 25th anniversary, Identity by Richard The, The Green Eyl \& E. Roon Kang, 2011. Right: MIT Media Lab Identity by Pentagram, Michael Bierut, 2014.

Lastly, a case of solid pervasive implementation is THNK, the Amsterdam School of creative leadership, whose identity was created by LAVA, 2012. 
The absence of the "I" in the name is the basis for the logo and for the imagery, used to enrich typography and illustrations. The "I" is used to create a palette of dot symbols used to replace the " $\mathrm{O}$ " in texts or as building blocks for illustrations and infographics (Fig. 6).

It's a clever example of flexibility where the continuous application is guaranteed by the strategic control practised by the organization itself.

These examples reveal that organizations, multi-dimensional in terms of their internal components and audiences, intend to portray and share these contents as value through the perceptual complexity of their visual representation.

Creating a "non-static" visual identity modulates appropriately their tone of voice to different audiences, translating complex information into flexible languages.

Visual systems rather than logo-based identities are, indeed, more oriented to the "process" than to the final result and set rules to be used rather than imposing a solution to be applied. The dynamic design reveals the underlying structures of a complex organization [7].

Compared to the concepts of stability, repeatability and consistency, strictly stated in the corporate identity manual [8], the new approach chooses fluent, expressive languages obtained through the customization of programming by actively involving the user-base of the organization who are transformed into co-authors [9].
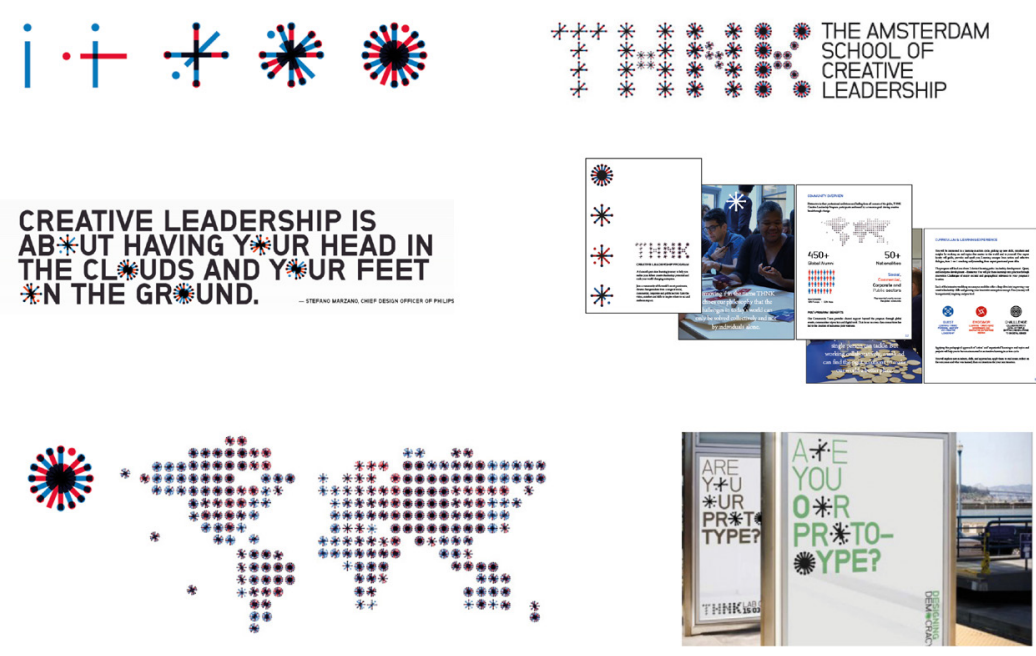

Fig. 6. THNK The Amsterdam School of Creative Leadership Identity by Lava, 2012.

\subsection{Further elements of discussion}

Despite the high level of innovation expressed by dynamic brands, careful attention must be paid when observing the digital environments where these identities are adopted. Although logo-centrism is no longer considered as an imperative, when 
comparing the original visual form of these case studies as stated by the designer, to the implementation disseminated on the Web (such as website as the main imagesharing ecosystem and social media), it's evident that, to be consistent and recognizable, digital environments, in the cases above, stress the main - static - shape of the identity rather than the variations.

\section{To conclude}

The realm of visual identities for educational institutes appears to be a suitable filed of experimentation of dynamic systems. The design of a dynamic systems provides for visual elements, their properties and processes of transformation [10]. It could be said that the realistic implementation of these components depends on the capability, on the talent of the group of communication inside the institution to be influential and able to apply professionally the design strategy.

Nevertheless, the most interesting aspect detectable is that a well-designed and managed dynamic brand doesn't require a unique final result, because it is founded on the principle of creating an open system, that could be selected by external people or influenced by external data. Through balancing constants and variables, according to the principle of searching "unity in variety" [11], implementation could be flexible or static depending on the demand.

\section{References}

1. Blauvelt, A., Lupton, E. (Ed.). (2011). Graphic Design: Now in Production. Minneapolis: Walker Art Center.

2. Anceschi, G., Chiappini, C. (2006). Hard, soft e smart: gli stili registici dell'identity design. Progetto Grafico, 9, pp. 108-111.

3. Lorenz, M. (2017). Des identités visuelle statiques aux identités visuelle flexibles. Graphisme en France 2017. Logos \& identités visuelles, 23, pp. 25-35.

4. Felsing, U. (2010). Dynamic identities in Cultural and Public Contexts. Zurich: Lars Müller Publisher.

5. van Nes, I., Hygues, P. (2013). Dynamic Identities. How to create a living brand. Netherland: Bis Publishers.

6. Torna, C. (2017). Pianta un logo. In Russo, D. (Ed). Identity the colors of project, Proceeding of the International Congress (pp. 90-95). Italia: Palermo University Press.

7. Guida, F.E. (2014). Identità visive generative. Programmare la corporate identity. In $A$ Matter of Design: Making Society trough Science and Technology, (pp. 111-125) Proceedings of the 5th STS Italia Conference. Italia: STS Italia Publishing.

8. Henrion, F.H.K., Parkin A. (1967). Design coordination and corporate image. London, New York: Studio Vista, Reinhold Publ. Corporation.

9. Chiappini, C., Sfligiotti, S. (2010). Open projects. Des identités non standard. Paris: Pyramid.

10. Gerstner, K. (2007) Designing Programmes (3rd ed.). Zurich: Lars Müller Publishers.

11. Maldonado, T. (1991). Disegno industriale: un riesame. Milano: Feltrinelli. 